\title{
Alkyl Substituted Cucurbit[6]uril Assisted Competitive Fluorescence Recognition of Lysine and Methionine in Aqueous Solution
}

\author{
Qinghong Bai, ${ }^{[a]}$ Shaowei Zhang, ${ }^{[a]}$ Hongrong Chen, ${ }^{[a]}$ Tao Sun, ${ }^{[a]}$ Carl Redshaw, ${ }^{[b]}$ Jian-Xin Zhang, ${ }^{[c]}$ \\ Xin-Long Ni, ${ }^{\text {[a] }}$ Gang Wei, ${ }^{[\mathrm{d}]}$ and Zhu Tao ${ }^{[a]}$
}

Dedication

\begin{abstract}
The use of competitive ratiometric fluorescence indicator displacement chemosensors derived from two alkyl substituted cucurbit[6]uril-based host-guest complexes is reported. In particular, the differing binding abilities of two cucurbit[6]uril derivatives towards the target analytes led to a useful ratiometric detection signal output for the discrimination of lysine and methionine versus the other tested $\alpha$-amino acids in aqueous solution.
\end{abstract}

Of all the organic and biological molecules known, $\alpha$-amino acids are one of the most important classes of building blocks for proteins and peptides. ${ }^{[1]}$ For example, lysine is closely related to the Krebs-Henseleit cycle and polyamine synthesis. ${ }^{[2]}$ High concentrations of this amino acid in the plasma and urine is indicative of congenital metabolic disorders, such as cystinuria or hyperlysinemia. ${ }^{[3]}$ Despite the existence of a few lysine selective fluorescent probes, ${ }^{[4]}$ their detection in a biological medium (aqueous solution) still remains a challenge. Methionine, one of two sulfurcontaining aliphatic examples of the $\alpha$-amino acids, plays several important roles in cell metabolism in the human body. Generally, alterations in the level of cellular thiols have been linked to a number of diseases, such as leucocyte loss, psoriasis, liver damage, cancer, and AIDS. ${ }^{[5]}$ Recently, chemosensors for cysteine (Cys), homocysteine (Hcy), and glutathione (GSH), which take advantage of the unique nucleophilicity of their thiol $(-\mathrm{SH})$ groups, have been developed, ${ }^{[6,7]}$ but also of limited use in aqueous solution. Furthermore, few sensors are available for the detection of methionine, which is attributed to the chemically inert thiol ether $\left(-\mathrm{CH}_{2} \mathrm{SCH}_{3}\right)$ group. ${ }^{[8]}$

On the other hand, with the fast development of hostguest chemistry in aqueous solution, analyte responsive macrocyclic host/dye systems are available. These can be

\footnotetext{
[a] Q. Bai, S. Zhang, H. Chen, Prof. Dr. X.-L. Ni

Key Laboratory of Macrocyclic and Supramolecular Chemistry of Guizhou Province, Guizhou University

Guiyang 550025 (China)

E-mail: longni333@163.com

[b] Prof. Dr. C. Redshaw

Department of Chemistry, University of Hull, Hull HU6 7RX, UK

[c] Prof. J.-X. Zhang

Key Laboratory of Chemistry for Natural Products of Guizhou Province, Guiyang 550002, China

[d] CSIRO Manufacturing, P.O. Box 218, Lindfield, NSW 2070, Australia
}

Supporting information for this article is given via a link at the end of the document. termed as host/dye fluorescence indicator displacement (FID) systems, and have attracted increasing attention in chemical sensing as convenient alternatives to traditional chemosensors. ${ }^{[9]}$ For example, recent pioneering work on macrocyclic receptors includes reports on cyclodextrin, calixarene, pillararene and cucurbituril-based host/dye pairs for FID, ${ }^{[10]}$ which are able to recognize and detect many important biologically and environmentally relevant species in aqueous solution such as $\mathrm{N}$-terminal aromatic residues and acetylcholines. ${ }^{[9]}$ However, to the best of our knowledge, nearly all of the reported FID sensing systems are based on a single fluorescence signal "on-off" or "offon" type, and have rarely been exploited for ratiometric fluorescence signals. Importantly, ratiometric fluorescence sensing is more reliable given that the ratio between two emission intensities is more accurate by external stimuli compared to a single wavelength. ${ }^{[11]}$

Cucurbit[n]urils, a family of molecular container hosts bearing a rigid hydrophobic cavity and two identical carbonyl fringed portals, have attracted increased interest from researchers given their superior molecular (e.g., cationic guest) recognition properties in aqueous media. ${ }^{[12]}$ For example, in 2008, Nau et al successfully constructed a dye/Q[6] based ratiometric FID for cadaverine by monitoring the enzymatic activity of lysine decarboxylase. ${ }^{[13]}$ However, the notoriously poor solubility of Q[6] in water greatly restricts the types of analytes that can be used and has hindered the development of cucurbuturils-based supramolecular chemosensors. It is against this background that two cucurbit[6]uril derivatives tetramethylcucurbit[6]uril (TMeQ[6] $)^{[14]}$ and hemimethylsubstituted cucurbit[6]uril (HMeQ[6]), ${ }^{[15]}$ both of which were previously found by our group to exhibit better solubility in aqueous media than the parent Q[6], are exploited as hosts to construct FID chemosensors (Figure 1). In particular, we report TMeQ[6] and $\mathrm{HMeQ[6]} \mathrm{host-guest} \mathrm{based} \mathrm{ratiometric}$ fluorescent FIDs for lysine and methionine in aqueous solution.

The cationic dye guest (G1) (Scheme 1) was recently reported by us to have excellent affinity and selectivity for the $\mathrm{NO}_{3}{ }^{-}$anion in acidic aqueous solution via the formation of nanoribbon-like aggregates. ${ }^{[16]}$ The positively charged G1 generates a significant ratiometric fluorescence signal in response to $\mathrm{NO}_{3}{ }^{-}$in the green/yellow spectral region. From a structural viewpoint, the two identical terminal octane aliphatic chains of the bispyridinium phenylene-vinylene 
(PPV) core-based dication G1 would provide an ideal axle for TMeQ[6] and $\mathrm{HMeQ[6]}$ to form stable inclusion complexes, giving rise to pseudorotaxanes which may further be exchanged by a competitive analyte guest (Scheme 1).

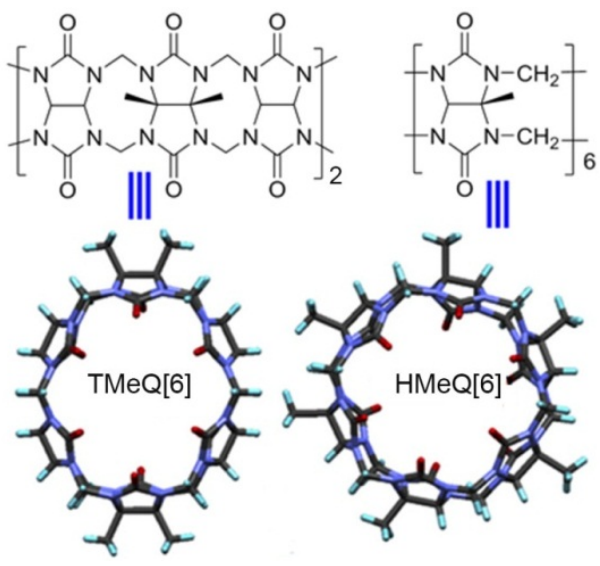

Figure1. Chemical and crystal structures of TMeQ[6] and HMeQ[6].

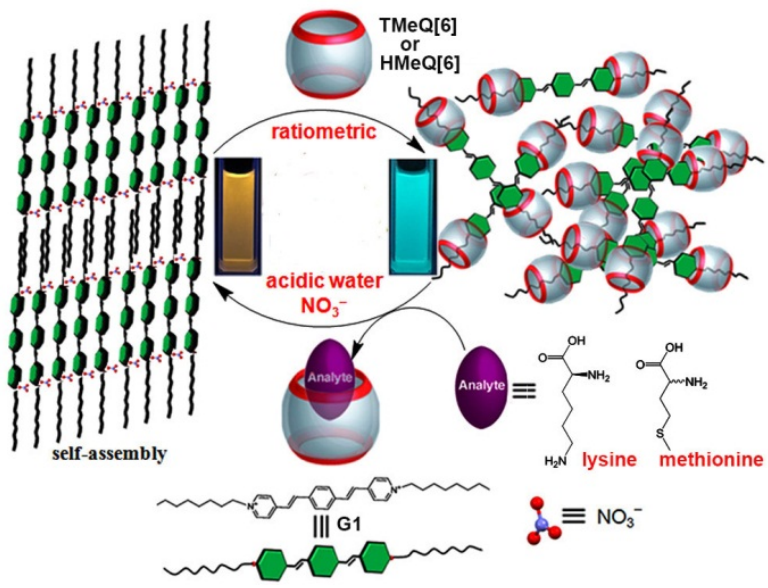

Scheme 1. (a) Illustration of the plausible fluorescence indicator displacement process based on host-guest interactions.

As shown in Figure 2, the fluorescence spectra of free $\mathrm{G1}$ exhibited a typical monomer emission at around $470 \mathrm{~nm}$ upon excitation at $398 \mathrm{~nm}$ at $\mathrm{pH} 6.0$ and a typical aggregation emission around $605 \mathrm{~nm}$ appeared in the presence of $\mathrm{NO}_{3}{ }^{-}$anions (20 equiv.). Upon addition of increasing concentrations of TMeQ[6] to the acidic aqueous solution (see from Figure 2 and FigureS1), the fluorescence intensity of the aggregation emission of $\mathrm{G} 1$ at $605 \mathrm{~nm}$ markedly decreased while the monomer emission intensity at $480 \mathrm{~nm}$ significantly increased and reached a plateau after addition of 2.0 equiv. of $\mathrm{TMeQ}[6]$. This result indicated that the aggregation of $\mathrm{G} 1 \cdot \mathrm{NO}_{3}{ }^{-}$was successfully disturbed by the TMeQ[6] host. In particular, compared to the max monomer emission intensity of $\mathrm{G} 1$ at $470 \mathrm{~nm}$, a red-shifted emission with a Stokes shift of about $15 \mathrm{~nm}$ was observed for the TMeQ[6] triggered host-guest interaction of $\mathrm{G1}$. This suggested the formation of an inclusion complex involving G1 with the cavity of TMeQ[6] (Figure S2). More specifically, an induced electronic redistribution of G1 was achieved by the polar carbonyl portals and hydrophobic cavity of TMeQ[6] after encapsulation, which further caused a strengthening of the D-A system, resulting in increased ICT and thereby accounting for the red-shift in the fluorescence spectra. ${ }^{[9 a]}$ In an effort to gain more detailed host-guest binding information for G1 with TMeQ[6], the binding behaviour was investigated by isothermal titration calorimetry (ITC). The fitted titration data revealed the formation of a 1:2 complex between $\mathrm{G} 1$ with TMeQ[6] and this is mainly derived from electrostatic forces and hydrophobic effects. The related binding constant $\left(K_{\mathrm{a}}\right)$ was calculated to be $(7.12 \pm 0.21) \times 10^{4} \mathrm{M}^{-1}$ (Figure S3). Similar fluorescence titration results and binding behaviour was observed between HMeQ[6] and $\mathrm{G} 1$, for which $K_{\mathrm{a}}$ was determined to be $(5.89 \pm 0.46) \times 10^{4} \mathrm{M}^{-1}$ (Figure S3). As mentioned previously, ${ }^{[16]}{ }^{1} \mathrm{H}$ NMR spectra of $\mathrm{G} 1$ in $\mathrm{D}_{2} \mathrm{O}$ was somewhat difficult to obtain due to a self-assembly aggregation process in aqueous solution. However, $\mathrm{HMeQ}[6]$ can be dissolved in DMSO, and thus the ${ }^{1} \mathrm{H}$ NMR titration experiments for $\mathrm{G} 1$ with $\mathrm{HMeQ}$ [6] were carried out in DMSO. As shown in Figure S4, upon gradual addition of $\mathrm{HMeQ}[6]$ to a solution of $\mathrm{G} 1$, the protons on the aromatic ring and the ethylene of G1 shifted up-field, whereas no significant chemical shift changes were observed for the alkyl chains. These results suggested that the phenyl and ethylene moieties are buried in the cavity of $\mathrm{HMeQ}[6]$, which is consistent with the red-shift fluorescence spectra of $\mathrm{G} 1$ in the presence of alkyl substituted Q[6]s.

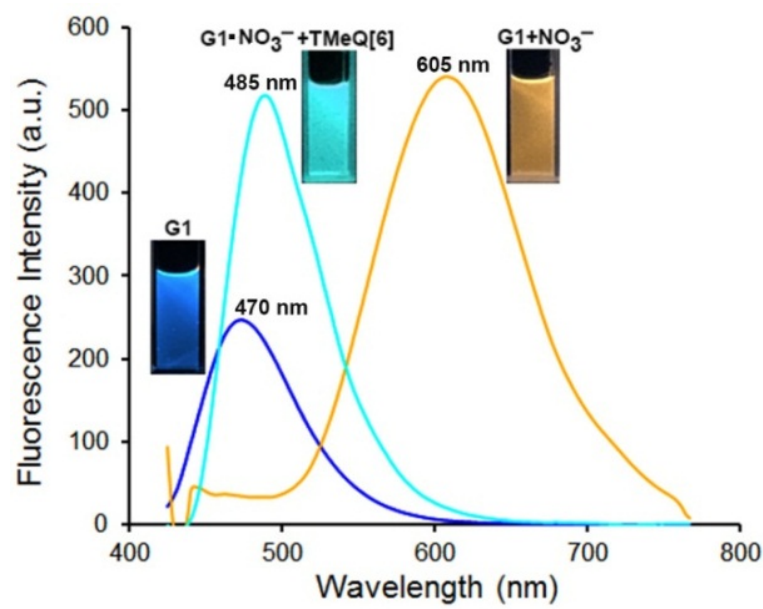

Figure 2. Fluorescence spectra of $\mathrm{G} 1 \quad(10 \mu \mathrm{M}), \mathrm{G} \cdot \mathrm{NO}_{3}{ }^{-}$and $\mathrm{G} 1 \cdot \mathrm{NO}_{3}^{-} / \mathrm{TMeQ}[6]$ in phosphate buffer solution $(\mathrm{pH} \mathrm{6.0)})$ at $298 \mathrm{~K}\left(\lambda_{\mathrm{ex}}=398\right.$ $\mathrm{nm})$.

However, upon addition of increasing concentrations of the parent $\mathrm{Q}[6]$ to the solution of $\mathrm{G} 1 \cdot \mathrm{NO}_{3}{ }^{-}$under the same 
conditions, as shown in Figure S1c, smaller fluorescence intensities changes are caused by Q[6] for both the monomer and aggregation emissions of $\mathrm{G} 1$ relative to TMeQ[6] and HMeQ[6]. This suggests that the parent $Q[6]$ has a lower affinity toward G1, which may be attributed to the electron donating effect of the alkyl substituents on TMeQ[6] and HMeQ[6]. In other words, the likely increased electron density and negativity of the carbonyl oxygen atom of the substituted glycoluril moiety versus that of the carbonyl oxygens on the parent Q[6], enables the former to adopt stronger ion-dipole interactions with the cationic guest G1. ${ }^{[17]}$

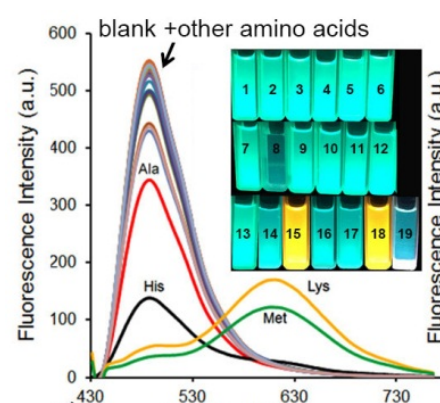

a) $\quad \begin{array}{cc}530 & 630 \\ & \text { Wavelength }(\mathrm{nm})\end{array}$

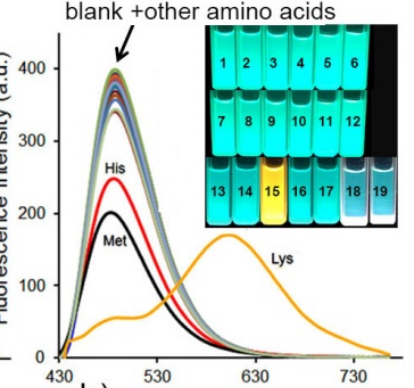

b) Wavelength $(\mathrm{nm})$
Figure 3. Fluorescence spectra and UV light $(365 \mathrm{~nm})$ colour of (a) $\mathrm{G} 1 \cdot \mathrm{NO}_{3}{ }^{-} / \mathrm{TMeQ}[6]$ and (b) $\mathrm{G} 1 \cdot \mathrm{NO}_{3}{ }^{-} / \mathrm{HMeQ}[6]$ in the presence of different amino acids $(50 \mu \mathrm{M})$ in phosphate buffer solution $(\mathrm{pH} 6.0)$ at $298 \mathrm{~K}\left(\lambda_{\mathrm{ex}}=398\right.$ $\mathrm{nm}$ ) (insert solution: blank (1), valine (2), proline (3), isoleucine (4), aspartic acid (5), leucine (6), asparagine (7), alanine (8), glutamine (9), threonine (10), serine (11), cysteine (12), glutamic acid (13), tryptophan (14), lysine (15), phenylalanine (16), arginine (17), methionine (18), and histidine (19)).

The absence of fluorescent spectral changes for $\mathrm{G} 1 \cdot \mathrm{NO}_{3}{ }^{-} / \mathrm{TMeQ}[6]$ and $\mathrm{G} 1 \cdot \mathrm{NO}_{3}{ }^{-} / \mathrm{HMeQ}[6]$ ([G1]: $10 \mu \mathrm{M}$; $\left[\mathrm{NO}_{3}{ }^{-}\right]: 200 \mu \mathrm{M}$; [(TMeQ[6])] or [(HMeQ[6])]: $\left.20 \mu \mathrm{M}\right)$ in aqueous solution $(\mathrm{pH}$ 6.0) upon addition of various biologically and environmentally relevant cations and anions (Figures S5-S6), indicated that neither of these hostguest complexes when utilized as FID chemosenors possessed the required recognition ability for these ions. However, in the presence of $18 \alpha$-amino acids including valine (Val), proline (Pro), isoleucine (Ile), aspartic acid (Asp), leucine (Leu), asparagine (Asn), alanine (Ala), glutamine $(\mathrm{Gln})$, threonine (Thr), serine (Ser), cysteine (Cys), glutamic acid (Glu), tryptophan (Trp), lysine (Lys), phenylalanine (Phe), arginine (Arg), methionine (Met), and histidine (His), as shown in Figure 3, no significant spectral changes were observed upon addition of aromaticterminated amino acids. A much weaker ratiometric response was exhibited compared to lysine when run at the same concentration as for alanine and histidine. By contrast, for methionine, ratiometric sensing was observed in the $\mathrm{G} 1 \cdot \mathrm{NO}_{3}{ }^{-} / \mathrm{TMeQ}[6]$ (Figure 3a) system, but was not observed in the $\mathrm{G} 1 \cdot \mathrm{NO}_{3}{ }^{-} / \mathrm{HMeQ}[6]$ system (Figure $3 \mathrm{~b}$ ). As shown in Figure S7, for a typical displacement titration, the addition of increasing concentrations of lysine to the solution of $\mathrm{G} 1 \cdot \mathrm{NO}_{3}{ }^{-} / \mathrm{TMeQ}[6]$ and $\mathrm{G} 1 \cdot \mathrm{NO}_{3}{ }^{-} / \mathrm{HMeQ}[6]$, and methionine to the solution of $\mathrm{G} 1 \cdot \mathrm{NO}_{3}{ }^{-} / \mathrm{TMeQ}[6]$, respectively, significantly reverts the fluorescence changes originally caused by the addition of the macrocycle. For example, a decrease of the host-guest interaction induced a monomer emission band at $480 \mathrm{~nm}$ with an accompanying increase in the aggregation emission to longer wavelength at around $605 \mathrm{~nm}$. An estimation of the interference of the selective response of the cucurbit[6]uril derivative based FID chemosensors for lysine and methionine was conducted in the presence of other amino acids (Figure S8). The fluorescence intensity was almost identical to that obtained in the absence of other interfering ions, indicating that the $\mathrm{G} 1 \cdot \mathrm{NO}_{3}{ }^{-} / \mathrm{TMeQ}[6]$ and $\mathrm{G} 1 \cdot \mathrm{NO}_{3}{ }^{-} / \mathrm{HMeQ}[6]$ systems can be used as an efficient selective chemosensors for both lysine and methionine. The detection limit of $\mathrm{G1} \cdot \mathrm{NO}_{3}{ }^{-} / \mathrm{TMeQ}[6]$ for Lys and Met were determined to be $2.79 \times 10^{-6} \mathrm{M}$ and $1.94 \times 10^{-6} \mathrm{M}$, respectively (Figure S9), and the detection limit of $\mathrm{G} 1 \cdot \mathrm{NO}_{3}{ }^{-} / \mathrm{HMeQ}[6]$ for Lys was found to be $2.81 \times 10^{-6} \mathrm{M}$ (Figure S10).

As mentioned previously, it is generally accepted that the relatively narrow cavity and portals of $Q[6]$ and its derivatives can only encapsulate protonated diaminoalkanes with high $K_{\mathrm{a}}$, for which the alkyl carbon chain is greater than 4 atoms. Therefore, it is not surprising that nearly all of the shorter alkyl chain terminal amino acids used in this study did not replace $\mathrm{G} 1$ from the cavity of TMeQ[6] or HMeQ[6]. By contrast, for lysine, owing to the 1,4-diaminobutane parent scaffold, there should be high complexation ability towards both TMeQ[6] and HMeQ[6] compared to $\mathrm{G} 1$. As a result, $\mathrm{G} 1$ was released by the target analytes from the host cavities into the acidic solution, and can then re-aggregate on association with $\mathrm{NO}_{3}{ }^{-}$. For methionine, given only a mono-amino function is appended to the structure, it is expected that only moderately stable complexes with $\mathrm{TMeQ}[6]$ or $\mathrm{HMeQ}[6]$ will be formed compared to lysine.

Table 1. Binding Constants $\left(\mathrm{K}_{\mathrm{a}}\right)$ and the relevant thermodynamic parameters for the complexation of the amino acids guests with TMeQ[6] and HMeQ[6] in aqueous solution at $\mathrm{pH} 6.0$ at $298.15 \mathrm{~K}$.

\begin{tabular}{ccccc}
\hline Complex & $n$ & $K_{\mathrm{a}}\left(\mathrm{M}^{-1}\right)$ & $\begin{array}{c}\Delta H^{\mathrm{o}} \\
\left(\mathrm{kJ} \cdot \mathrm{mol}^{-1}\right)\end{array}$ & $\begin{array}{c}\mathrm{T} \Delta S^{\circ} \\
\left(\mathrm{kJ} \cdot \mathrm{mol}^{-1}\right)\end{array}$ \\
\hline Lys$\cdot \mathrm{TMeQ}[6]$ & 1.07 & $4.52( \pm 0.41) \times 10^{6}$ & $-13.95 \pm 0.27$ & $17.44 \pm 0.13$ \\
Met•TMeQ[6] & 0.97 & $8.27( \pm 0.67) \times 10^{5}$ & $-33.75 \pm 0.06$ & $-10.43 \pm 0.22$ \\
Lys•HMeQ[6] & 0.96 & $6.19 \pm(0.33) \times 10^{5}$ & $-10.11 \pm 0.41$ & $13.90 \pm 0.15$ \\
Met•HMeQ[6] & 1.04 & $9.98 \pm(0.45) \times 10^{4}$ & $-41.26 \pm 0.37$ & $-19.16 \pm 0.11$ \\
\hline
\end{tabular}

In order to further confirm the above hypothesis and also to better understand the binding between lysine, methionine and the alkyl substituted cucurbit[6]urils, ITC titration experiments were conducted. As shown in Table 1 and Figures $\mathrm{S} 11-\mathrm{S} 12$, the fitted data and the mole ratio results 
indicated that the host-guest inclusion mole ratio between TMeQ[6], HMeQ[6] and the amino acids is 1:1. As expected, TMeQ[6] and HMeQ[6] exhibit similar selective binding tendencies toward lysine and methionine. In particular, the $K_{\mathrm{a}}$ for TMeQ[6] and HMeQ[6] with lysine is larger than that for $\mathrm{G} 1 \cdot \mathrm{NO}_{3}{ }^{-} / \mathrm{TMeQ}[6]$ and $\mathrm{G} 1 \cdot \mathrm{NO}_{3}{ }^{-} / \mathrm{HMeQ}[6]$, respectively, which lead to the higher observed dye displacement efficiency for lysine. Interestingly, it is worth noting that TMeQ[6] and HMeQ[6] exhibit lower binding ability toward methionine as compared to lysine. However, the $K_{a}$ of HMeQ[6] with methionine is almost the same binding level as that observed for $\mathrm{G} 1 \cdot \mathrm{NO}_{3}{ }^{-} / \mathrm{HMeQ}[6]$, which means the competitive binding of methionine might not lead to the complete release of $\mathrm{G1}$ from the cavity of $\mathrm{HMeQ}[6]$. As a result, $\mathrm{G} 1 \cdot \mathrm{NO}_{3}{ }^{-} / \mathrm{HMeQ}[6]$ displays FID selectivity for lysine but no response for methionine. Consequently, the ability of $\mathrm{G} 1 \cdot \mathrm{NO}_{3}{ }^{-} / \mathrm{TMeQ}[6]$ and $\mathrm{G} 1 \cdot \mathrm{NO}_{3}{ }^{-} / \mathrm{HMeQ}[6]$ to act as FID chemosensors for lysine and methionine holds more potential than for the various other amino acids investigated (Figure 4) in systems such as in serum (Figure S13).

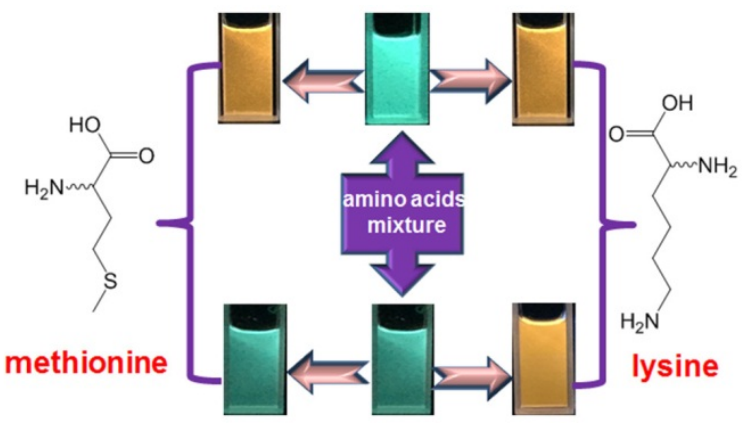

Figure 4 Illustration of the cooperation discrimination of lysine and methionine by $\mathrm{G} 1 \cdot \mathrm{NO}_{3}{ }^{-} / \mathrm{TMeQ}[6]$ and $\mathrm{G} 1 \cdot \mathrm{NO}_{3}{ }^{-} / \mathrm{HMeQ}[6]$ as $\mathrm{FID}$ chemosensors in aqueous solution.

In order to obtain more detail information and evidence for the encapsulation selectivity for the targeting analytes, the binding property of TMeQ[6] and HMeQ[6] with various amino acids were carefully evaluated by ${ }^{1} \mathrm{H}$ NMR spectroscopic titration experiments. As show in Figures S14-16, upon addition of increasing concentrations of TMeQ[6] or HMeQ[6] to the acidic aqueous solution of 18 amino acids, no obvious resonance peak changes corresponding to the protons of the tested amino acids were observed, apart from weak proton responses for leucine, phenylalanine, and histidine in the presence of TMeQ[6] or HMeQ[6]. This contrasts with the significant upfield shift for the aliphatic protons on the Lys and Met moieties. This result clearly demonstrated that an amino aliphatic moiety of the Lys and a sulfur-containing amino aliphatic group of the Met were specifically included by the alkyl substituted Q[6]s cavity. On the other hand, studies by Xiao et al recently revealed that the aliphatic molecule fits better into the ellipsoidal cavity of TMeQ[6] rather than the rounder one as found in the parent Q[6]. ${ }^{[18]}$ Therefore, the higher binding constant of TMeQ[6] with lysine and methionine compared to $\mathrm{HMeQ}[6]$ in the present study could also be attributed to the ellipsoidal hydrophobic cavity of TMeQ[6], which may provide a more appropriate geometric structure to fit with the alkyl chain terminal amino acids in the cavity.

In conclusion, we have constructed a new type of ratiometric fluorescent chemosensor based on the hostguest interactions of $\mathrm{TMeQ}[6]$ and $\mathrm{HMeQ}[6]$ with the fluorophore guest G1 as an FID system for the detection of lysine and methionine in the presence of $\mathrm{NO}_{3}{ }^{-}$anions in acidic aqueous solution. Fluorescence spectral changes suggested that $\mathrm{G} 1 \cdot \mathrm{NO}_{3}{ }^{-} / \mathrm{TMeQ}[6]$ displays high selectivity for both lysine and methionine, whereas $\mathrm{G} 1 \cdot \mathrm{NO}_{3}{ }^{-} / \mathrm{HMeQ}[6]$ appears to be solely sensitive towards lysine. This is due to the ellipsoidal cavity of TMeQ[6] being more suitable for the inclusion of guests containing alkyl chain moieties compared to that of the rounder one present in $\mathrm{HMeQ}[6]$. As a result, lysine and methionine could be further discriminated by the cooperation of $\mathrm{G} 1 \cdot \mathrm{NO}_{3}{ }^{-/ T M e Q}[6]$ and $\mathrm{G1} \cdot \mathrm{NO}_{3}{ }^{-} / \mathrm{HMeQ}[6]$. There are few sensors reported for the detection of methionine, which is attributed to the chemically inert thiol ether $\left(-\mathrm{CH}_{2} \mathrm{SCH}_{3}\right)$ group. We thus believe that this present work will provide a new design strategy for the sensing, detection, and recognition of $\alpha$ amino acids via the use of a ratiometric fluorescence signal.

\section{Acknowledgements}

This work was supported by National Natural Science Foundation of China (No. 21303026), "Chun-Hui" Fund of Chinese Ministry of Education (Nos. Z2016011 and Z2015002). Guizhou Province (Nos. 20165656, 20132150) and Guizhou University (No. 20127027). CR thanks the EPSRC for the award of a travel grant.

Keywords: ratiometric chemosensor $\cdot$ cucurbituril lysine $•$ methionine competitive recognition

[1] V. I. Chalova, I. B. Zabala-Diaz, C. L.Woodward, S. C. Ricke, World J. Microbiol. Biotechnol. 2007, 24, 353.

[2] a) H. Yoshida, Y. Nakano, K. Koiso, H. Nohta, J. Ishida, M. Yamaguchi, Anal. Sci. 2001, 17, 107; b) D. Wellner and A. Meister, Annu. Rev. Biochem. 1981, 50, 911 .

[3] a) P. Felig, Annu. Rev. Biochem. 1975, 44, 933; b) C. Hirayama, K. Suyama, Y. Horie, K. Tanimoto, S. Kato, Biochem. Med. Metab. Biol. 1987, 38, 127.

[4] a) M. Wehner, T. Schrader, P. Finocchiaro, S. Failla, G. Consiglio, Org. Lett. 2000, 2, 605; b) S. Sasaki, A. Hashizume, D. Citterio, E. Fujii, K. Suzuki, Tetrahedron Lett. 2002, 43, 7243; c) K. Secor, J. Plante, C. Avetta, T. Glass, J. Mater. Chem. 2005, 15, 4073; d) C. P. Mandl, B. Konig, J. Org. Chem. 2005, 
70, 670; e) J. Wang, P. Zhang, C. M. Li, Y. F. Li, C. Z. Huang, Biosens. Bioelectron. 2012, 34, 197; f) J.T. Hou, K. Li, B.-Yu Liu, Y.-X. Liao and X.-Q. Yu, Tetrahedron 2013, 69, 2118; g) Y. Zhou, J. Won, J. Y. Lee, J. Yoon, Chem. Commun. 2011,47, 1997; h) S. Lohar, D. A. Safin, A. Sengupta, A. Chattopadhyay, J. S. Matalobos, M. G. Babashkina, K. Robeyns, M. P. Mitoraj, P. Kubisiak, Y. Garcia, D. Das, Chem. Commun. 2015, 51, 8536; i) J. Tong, Y. Wang, J. Mei, J. Wang, A. Qin, J. Z. Sun, B. Z. Tang, Chem. Eur. J. 2014, 20, 4661.

[5] a) L. A. Herzenberg, S. C. De Rosa, J. G. Dubs, M. Roederer, M. T. Anderson, S. W. Ela, S. C. Deresinski, L. A. Herzenberg, Proc. Natl. Acad. Sci. U. S. A. 1997, 94, 1967; b) D. M. Townsend, K. D. Tew, H. Tapiero, Biomed. Pharmacother. 2003, 57, 145.

[6] a) X. Chen, Y. Zhou, X. Peng, J. Yoon, Chem. Soc. Rev. 2010, 39, 2120; b) C. Yin, F. Huo, J. Zhang, R. Martínez-Máñez, Y. Yang, H. Lva, S. Li, Chem. Soc. Rev. 2013, 42, 6032; c) K. Wang, H. Peng, B. Wang, J. Cell. Biochem. 2014, 115, 1007.

[7] a) J. Liu, Y.-Q. Sun, Y. Huo, H. Zhang, L. Wang, P. Zhang, D. Song, Y. Shi, W. Guo, J. Am. Chem. Soc. 2014, 136, 574; b) S.-Y. Lim, K.-H. Hong, D. I. Kim, H. Kwon, H.-J. Kim, J. Am. Chem. Soc. 2014, 136, 7018; c) D. Lee, G. Kim, J. Yin, J. Yoon, Chem. Commun. 2015, 51, 6518; d) Y. Yuan, J. Zhang, M. Wang, B. Mei, Y. Guan, G. Liang, Anal. Chem. 2013, 85, 1280; e) X. Xiong, F. Song, G. Chen, W. Sun, J. Wang, P. Gao, Y. Zhang, B. Qiao, W. Li, S. Sun, J. Fan, X. Peng, Chem. Eur. J. 2013, 19, 6538; f) L. Y. Niu, Y. S. Guan, Y. Z. Chen, L. Z. Wu, C. H. Tung, Q. Z. Yang, J. Am. Chem. Soc. 2012, 134, 18928; g) M. H. Lee, J. H. Han, P. S. Kwon, S. Bhuniya, J. Y. Kim, J. L. Sessler, C. Kang, J. S. Kim, J. Am. Chem. Soc. 2012, 134, 1316; h) X. Yang, Y. Guo, R. Strongin, Angew. Chem., Int. Ed. 2011, 50, 10690; i) L. Song, Q. Sun, N. Wang, Z. Chen, W. Zhang, J. Qian, Anal. Methods 2015, 7, 10371; j) H. Zhang, R. Liu, J. Liu, L. Li, P. Wang, S. Q. Yao, Z. Xu, H. Sun, Chem. Sci. 2016, 7, 256; k) Y. Tang, H.-R. Yang, H.B. Sun, S.-J. Liu, J.-X. Wang, Q. Zhao, X.-M. Liu, W.-J. Xu, S.-B. Li, W. Huang, Chem. Eur. J. 2013, 19, 1311; 1) X. Jia, J. Li, E. Wang, Chem. Eur. J. 2012, 18 13494; m) F. Wang, Z. Guo, X. Li, X. Li, C. Zhao, Chem. Eur. J. 2014, 20, 11471; n) X. Zhou, X. Jin, G. Sun, X. Wu, Chem. Eur. J. 2013, 19, 7817; 0)Y. Liu, X. Lv, J. Liu, Y.-Q. Sun, W. Guo, Chem. Eur. J. 2015, $21,4747$.

[8] A. Buryak, K. Severin, Angew. Chem., Int. Ed. 2004, $43,4771$.

[9] a) R. N. Dsouza, U. Pischel, W. M. Nau, Chem. Rev. 2011, 111, 7941; (b) L. You, D. Zha, E. V. Anslyn, Chem. Rev. 2015, 115, 7840.

[10] a) G. Ghale, W. M. Nau, Acc. Chem. Res. 2014, 47, 2150 ; b) S. Sun, F. Li, F. Liu, J. Wang, X. Peng, Sci. Rep. 4, No. 3570; c) G.H. Aryal, L.Huang, K. W. Hunter, RSC Adv. 2016, 6, 82566; d) F. Biedermann, D. Hathazi, W. M. Nau, Chem. Commun. 2015, 51 , 4977; e) K. Liu, Y. Yao, Y. Kang, Y. Liu, Y. Han, Y. Wang, Z. Li, X. Zhang, Sci. Rep. 3, No. 2372; f) F. Biedermann, E. Elmalem, I. Ghosh, W. M. Nau, O. A. Scherman, Angew. Chem., Int. Ed. 2012, 51, 7739; g) D.-S. Guo, Y. Liu, Acc. Chem. Res. 2014, 47, 1925; h)
B. Hua, L. Shao, G.Yu and F. Huang, Chem. Commun. 2016, 52, 10016; i) G. Liang, F. Ren, H. Gao, Q. Wu, F. Zhu, B. Z. Tang, ACS Sens. 2016, 1, 1272; j) G. Zhao, L. Yang, S. Wu, H. Zhao, E Tanga, C.-P. Li, Biosens. Bioelectron. 2017, 91, 863; k) L. Yang, H. Zhao, Y. Li, Y. Zhang, H. Ye, G. Zhao, X. Ran, F. Liu, C.-P. Li, Biosens. Bioelectron., 2017, 87, 737; 1) L. Yang, X. Xie, L. Cai, X. Ran, Y. Li, T. Yin, H. Zhao, C.-P. Li, Biosens. Bioelectron., 2016, 82, 146; m) L. Yang, H. Zhao, Y. Li, X. Ran, G. Deng, X. Xie, C.-P. Li, ACS Appl. Mater. Inter. 2015, 7, 26557; n) H. Ye, L. Yang, G. Zhao, Y. Zhang, X. Ran, S. Wu, S. Zou, X. Xie, H. Zhao, C.-P. Li, RSC Adv. 2016, 6, 79350.

[11] a) J. Fan, M. Hu, P. Zhan, X. Peng, Chem. Soc. Rev. 2013, 42, 29; b) D. Srikun, E. W. Miller, D. W. Domaille, C. J. Chang, J. Am. Chem. Soc. 2008, 130, 4596; c) E. M. Nolan, S. J. Lippard, J. Am. Chem. Soc. 2007, 129, 5910; d) Y. Zhang, X. Guo, W. Si, L. Jia, X. Qian, Org. Lett. 2008, 10, 473; e) L. Huang, S.-W. Tam-Chang, Chem. Commun. 2011, 47, 2291; f) G. H. Aryal, L. Huang, K. W. Hunter, RSC Adv. 2016, 6, 76448.

[12] a) J. W. Lee, S. Samal , N. Selvapalam , H.-J. Kim, K. Kim, Acc. Chem. Res. 2003, 36, 621; b) J. Lagona, P. Mukhopadhyay, S. Chakrabarti, L. Isaacs, Angew. Chem., Int. Ed. 2005, 44, 4844; c) E. Masson, X. Ling, R. Joseph, L. Kyeremeh-Mensah, X. Lu, RSC Adv. 2012, 2, 1213; d) X.-L. Ni, Y. Chen, Y. Yang, Z. Tao, J. Am. Chem. Soc. 2016, 138, 6177; e) S. J. Barrow, S Kasera, M. J. Rowland, J. del Barrio, O. A. Scherman, Chem. Rev. 2015, 115, 12320; f) K. I. Assaf, W. M. Nau, Chem. Soc. Rev. 2015, 44, 39; g) D. Shetty, J. K. Khedkar, K. M. Park, K. Kim, Chem. Soc. Rev. 2015, 44, 8747; h) Q. Song, Y. Jiao, Z. Wang, X. Zhang, Small, 2016, 12, 24; i) J. Tian, L. Chen, D.-W. Zhang, Y. Liu, Z.-T. Li, Chem. Commun. 2016, 52, 6351; j) M. A. Gamal-Eldin, D. H. Macartney, Org. Biomol. Chem. 2013, 11, 488; k) M. V. Rekharsky, H. Yamamura, Y. H. Ko, N. Selvapalam, K. Kim, Y. Inoue, Chem. Commun. 2008, 2236.

[13] A. Praetorius, D. M. Bailey, T. Schwarzlose, W. M. Nau, Org. Lett. 2008, 10, 4089.

[14] Y. J. Zhao, S. F. Xue, Q. J. Zhu, Z. Tao, J. X. Zhang, Z. B. Wei, L. S. Long, M. L. Hu, H. P. Xiao, A. I. Day, Chin. Sci. Bull. 2004, 49, 1111.

[15] J. X. Lin, Y. Q. Zhang, J. Zhang, S. F. Xue, Q. J. Zhu, Z. Tao, J. Mol. Struct. 2008, 875, 442.

[16] Y. Yang, S. Chen, X.-L. Ni, Anal. Chem. 2015, 87, 7461.

[17] a) X.-L. Ni, J.-X. Lin, Y.-Y. Zheng, W.-S. Wu, Y.-Q. Zhang, S.-F. Xue, Q.-J. Zhu, Z. Tao, A. I. Day, Cryst. Growth Des. 2008, 8, 3446; b) Z.-F. Li, F. Wu, F.-G. Zhou, X.-L. Ni, X. Feng, X. Xiao, Y.-Q. Zhang, S.-F. Xue, Q.-J. Zhu, L. F. Lindoy, J. K. Clegg, Z. Tao, G. Wei, Cryst. Growth Des. 2010, 10, 5113; c) Z.-F. Li, L.-L. Liang, F. Wu, F.-G. Zhou, X.-L. Ni, X. Feng, X. Xiao, Y.-Q. Zhang, S.-F. Xue, Q.-J. Zhu, J. K. Clegg, Z. Tao, L. F. Lindoy, G. Wei, CrystEngComm 2013, 15, 1994.

[18] B. Yang, L.-M. Zheng, Z.-Z. Gao, X. Xiao, Q.-J. Zhu, S.-F. Xue, Z. Tao, J.-X. Liu, G. Wei, J. Org. Chem. 2014, 79, 11194. 
Entry for the Table of Contents (Please choose one layout)

Layout 2:

\section{COMMUNICATION}

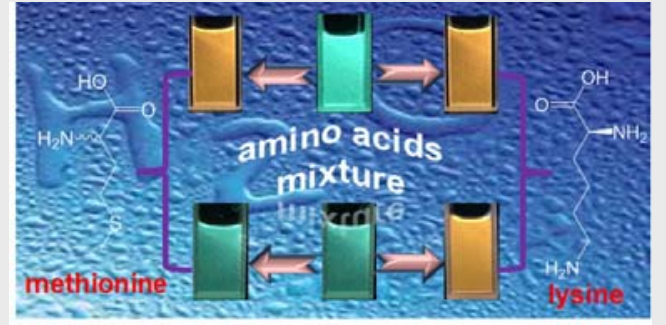

Two cucurbit[6]uril based ratiometric fluorescent indicator displacement systems were exploited for the discrimination of lysine and methionine versus other tested aamino acids in aqueous solution.
Qinghong Bai, ${ }^{[a]}$ Shaowei Zhang, ${ }^{[a]}$ Hongrong Chen, ${ }^{[a]}$ Tao Sun, ${ }^{[a]}$ Carl Redshaw, ${ }^{[b]}$ Jian-Xin Zhang, ${ }^{[c]}$ Xin-Long $\mathrm{Ni}$, ${ }^{[a]}$ Gang Wei, ${ }^{[d]}$ and Zhu Tao ${ }^{[a]}$

Page No. - Page No.

Alkyl Substituted Cucurbit[6]uril Assisted Competitive Fluorescence Recognition of Lysine and Methionine in Aqueous Solution 